Ren-Bin Lin · Shin-Min Shih

\title{
Kinetic analysis of the hydrogen oxidation reaction on Pt-black/Nafion electrode
}

Received: 4 February 2005/ Revised: 8 March 2005/ Accepted: 13 March 2005 / Published online: 13 December 2005

(C) Springer-Verlag 2005

\begin{abstract}
The hydrogen oxidation reaction on Pt-black/ Nafion electrode was investigated using a rotating disk electrode and cyclic voltammetry technique. The voltammetric results demonstrated that the electrode can be prepared with good reproducibility and that Ptblack particles without direct contact with Nafion were still electrochemically active in taking part in the $\mathrm{H}$ adsorption/desorption process. For hydrogen oxidation, the limiting current density was reduced by the presence of Nafion coating. The $\mathrm{H}_{2}$ diffusion resistance in Nafion film was avoided when the film thickness was less than $0.2 \mu \mathrm{m}$ for a Pt-black loading of $20 \mu \mathrm{g}$. Moreover, the uncertainties in the kinetic results were discussed.
\end{abstract}

Keywords Platinum black - Nafion - Rotating disk electrode $\cdot$ Hydrogen oxidation $\cdot$ Fuel cells

\section{List of symbols}

$B$

BET:

$C_{\text {f: }}$

$C_{0}$ :

$D$ :

$D_{\mathrm{f}}:$

E:

EW:

$F$ :

$\mathrm{GC}$ :

I:

$i_{\mathrm{d}}:$

$i_{\mathrm{f}}:$

Levich constant, $\mathrm{mC} \mathrm{cm} \mathrm{mol}^{-1}$

Brunauer-Emmett-Teller method

$\mathrm{H}_{2}$ concentration in film, mol cm $\mathrm{cm}^{-3}$

$\mathrm{H}_{2}$ solubility in electrolyte, mol $\mathrm{cm}^{-3}$

$\mathrm{H}_{2}$ diffusivity in electrolyte, $\mathrm{cm}^{2} \mathrm{~s}^{-1}$

$\mathrm{H}_{2}$ diffusivity in film, $\mathrm{cm}^{2} \mathrm{~s}^{-1}$

potential of an electrode versus a reference, $\mathrm{V}$

equivalent weight

Faraday constant, $\mathrm{C} \mathrm{mol}^{-1}$

glassy carbon

amplitude of an ac current, $\mathrm{mA}$

diffusion-limited current density, $\mathrm{mA} \mathrm{cm}^{-2}$

film-diffusion limited current density, $\mathrm{mA} \mathrm{cm}{ }^{-2}$

R.-B. Lin · S.-M. Shih ( $\square)$

Department of Chemical Engineering,

National Taiwan University, 106 Taipei, Taiwan

E-mail: smshih@ntu.edu.tw

Tel.: + 886-2-23633974

Fax: + 886-2-23623040 $i_{\mathrm{k}}: \quad$ kinetic current density, $\mathrm{mA} \mathrm{cm}^{-2}$

$i_{\mathrm{m}}$ : $\quad$ measured limiting current density,

$\mathrm{mA} \mathrm{cm}^{-2}$

$L: \quad$ film thickness, $\mu \mathrm{m}$

$n: \quad$ the number of electrons involved in the reaction, dimensionless

PEMFCs: proton exchange membrane fuel cells

$Q_{\mathrm{H}}$ : hydrogen adsorption/desorption charge, $\mathrm{mC}$

RDE: rotating disk electrode

RHE: reversible hydrogen electrode

SCE: $\quad$ saturated calomel electrode

XRD: $\quad$ X-ray diffraction

$Y_{0}: \quad$ Levich intercept, $\mathrm{mA}^{-1} \mathrm{~cm}^{2}$

$v: \quad$ kinematic viscosity, $\mathrm{cm}^{2} \mathrm{~s}^{-1}$

$\omega: \quad$ rotation rate, rpm

\section{Introduction}

Fuel cells are promising to be an energy source, as they show higher energy conversion efficiency due to the direct conversion of chemical energy into electrical energy. In particular, proton exchange membrane fuel cells (PEMFCs), operating at relatively low temperatures with low exhaust, can be miniaturized $[1,2]$ and are expected to come into practical application as power sources for portable, stationary and transportable uses [1-3].

As of today, platinum still serves as the most widespread electrocatalyst in fuel cells [1-3]. However, catalysts made of $\mathrm{Pt}$ are very expensive and lead to a significant cost problem. Thus, many research works have focused on enhancing the catalyst activity in order to lower the precious metal loading. Highly dispersed $\mathrm{Pt}$ black and $\mathrm{Pt}$ nanoparticles supported on carbon $(\mathrm{Pt} / \mathrm{C})$ are found to be highly active due to their high specific surface areas [1-3]. The way of incorporating the polymer 
electrolyte (e.g. Nafion) into the catalyst layer has been found to markedly affect the catalyst utilization [4-8].

In studying the effect of the polymer electrolyte on the electrocatalytic activity of an electrode, most efforts focus on optimization as a function of Nafion content [9-13]. Several groups have investigated the influence of the polymer electrolyte film on the mass transport and the reaction kinetics. The electrode surface reactions, including $\mathrm{H}_{2}$ oxidation [13, 14] and $\mathrm{O}_{2}$ reduction [1517], were investigated mainly for polymer electrolyte modified smooth Pt electrodes. So far, little attention has been paid to the reactions taking place at electrodes consisting the dispersed Pt-black or $\mathrm{Pt} / \mathrm{C}$ catalyst particles and the solid polymer electrolyte.

Recently, an ingenious and convenient half-cell method using a rotating disk electrode (RDE) configuration has been employed to measure the electrocatalytic activity of catalysts under fuel cell relevant conditions [18-22]. In this method, both catalyst powder and recast Nafion are immobilized on a rotating disk substrate, forming a membrane electrode assembly similar to that used in fuel cells. Gloaguen et al. [18] and Gojkovic et al. [19] deposited the catalyst powder and Nafion onto a glassy carbon (GC) RDE at the same time by using a Nafion solution containing the catalyst suspension. Whereas, Schmidt et al. [20, 21] deposited the catalyst $(20 \mathrm{wt} \% \mathrm{Pt} / \mathrm{C}$ ) powder first and then coated the catalyst layer with a Nafion film. Generally speaking, because the mass transport process in a RDE setup is well known and can be controlled, the RDE method makes the determination of the kinetic parameters from the measured current much easier [22].

In this work, the hydrogen oxidation reaction on the Pt-black/Nafion electrode was investigated using a RDE and cyclic voltammetry (CV) technique. The electrocatalytic activity of the catalyst and the diffusion resistance of the Nafion film were evaluated. The reproducibility of the electrode preparation and the uncertainties in the kinetic results were also examined.

\section{Experimental}

\section{Materials}

A Nafion solution containing $5 \mathrm{wt} \%$ of Nafion dissolved in the mixture of isopropanol and water (1100 EW, Ion Power) was used to recast Nafion film. Pt-black (HiSPEC $^{\mathrm{TM}} 1000$, Johnson Matthey) was used as the dispersed catalyst. GC disk electrode (disk area $=0.1963 \mathrm{~cm}^{2}$ and shroud area $=1.131 \mathrm{~cm}^{2}$, Pine Instruments) was served as the substrate for the deposition of the catalyst. The disk was polished with a $0.05 \mu \mathrm{m}$ alumina powder (CHI Instruments) before use. The electrolyte was $0.5 \mathrm{M} \mathrm{H}_{2} \mathrm{SO}_{4}$ solution prepared form concentrated sulfuric acid (J.T. Baker) and ultrapure water (18 $\mathrm{M} \Omega$, Millipore). High purity $\mathrm{H}_{2}$ gas $(99.999 \%$, San-Fu) was used.

\section{Electrode preparation}

An aqueous catalyst suspension of $2 \mathrm{mg} \mathrm{ml}^{-1}$ was prepared by mixing $50 \mathrm{mg}$ of Pt-black and $25 \mathrm{ml}$ of deionized water under ultrasonication for about $10 \mathrm{~min}$. Diluter catalyst suspensions, which were necessary to form thinner catalyst layer, were prepared following a similar process with lower catalyst weights. About $12.5 \sim 20 \mu \mathrm{l}$ of the catalyst suspension was pipetted onto the GC disk surface and dried under room temperature. After the catalyst was dry, $20 \mu \mathrm{l}$ of Nafion solution was put on the top of the catalyst layer. Subsequent annealing in a vacuum oven $\left(70{ }^{\circ} \mathrm{C}\right)$ was made for at least $40 \mathrm{~min}$ to evaporate the residual solvent in the resulting thin-film electrode. This annealing renders the stable films insoluble and with sufficient strength to bind the catalyst particles [23]. The concentration of Nafion solution was varied by diluting the $5 \mathrm{wt} \%$ Nafion solution with isopropanol to yield recast films with thicknesses ranging from 0.08 to $8 \mu \mathrm{m}$. The film thickness was calculated from the mass and the surface area of the recast film, assuming a dry Nafion density of $1.98 \mathrm{~g} \mathrm{~cm}^{-3}[13,22]$. About $90 \%$ of the shroud area was found to be covered by the Nafion coating, thus the geometric surface area of the film was estimated to be $1 \mathrm{~cm}^{2}$. The film thickness was further measured using a surface texture profilometer (Dektak 3030, Sloan Technology), and the difference between the measured and calculated values was about $6 \%$.

\section{Electrochemical characterization}

A conventional three-compartment glass cell with a saturated calomel reference electrode (SCE) and a Pt foil counter electrode was used to study the electrochemical behaviors of the RDEs. Electrochemical measurements were conducted at room temperature $\left(25 \pm 1{ }^{\circ} \mathrm{C}\right)$ using a potentiostat (Autolab PGSTAT30, Ecochemie) with a computer-controlled general-purpose electrochemical system (GPES). Throughout this study, all potentials were referred to the reversible hydrogen electrode (RHE) scale. Before electrochemical characterization, the electrode was immersed for $8 \sim 10 \mathrm{~h}$ in the deaerated $0.5 \mathrm{M} \mathrm{H}_{2} \mathrm{SO}_{4}$ solution, which exhibited a very similar $\mathrm{pH}$ value to that of the Nafion film. Characteristic cyclic voltammograms $(\mathrm{CV})$ were obtained after cycling the potential of the electrode between 0 and $1.2 \mathrm{~V}$ vs. RHE for $1 \mathrm{~h}$. This long run-in period was necessary to obtain stable and reproducible data. Experiments for $\mathrm{H}_{2}$ oxidation on the rotating thin-film electrodes were performed in the $\mathrm{H}_{2}$-saturated $0.5 \mathrm{M} \mathrm{H}_{2} \mathrm{SO}_{4}$ electrolyte at several rotation rates in the range from 400 to $3,600 \mathrm{rpm} . \mathrm{H}_{2}$ was passed through the solution for $40 \mathrm{~min}$ before the experiment started and above the solution during the experiment. The potential of the electrode was changed between 0 and $0.5 \mathrm{~V}$ vs. RHE at a scan rate of $5 \mathrm{mV} \mathrm{s}^{-1}$. The retardation effect attributed to the adsorption of ionic contaminants or 
oxygen-containing species introduced by Nafion coating [21] was not observed to significantly affect the measured currents.

Physical characterization

The X-ray diffraction (XRD) pattern of the Pt-black was obtained with Mac Science M03XHF X-ray diffractometer with $\mathrm{Cu}$ target. The specific surface area of the catalyst was determined from the nitrogen adsorption data by the Brunauer-Emmett-Teller (BET) method, using a Micromeritics ASAP 2010 analyzer.

\section{Results and discussion}

Physical characterization of Pt-black

The Pt-black as received exhibited XRD peaks at $2 \theta$ of $39.98,46.54$, and 67.86, which are characteristic for crystal planes of Pt (111), Pt (200), and Pt (220), respectively, indicating a face centered cubic $(f c c)$ lattice. The average crystal size of Pt-black, $9.4 \mathrm{~nm}$, was obtained from the broadening of the Pt (111) peak using the Scherrer equation [24].

The BET surface area of Pt-black was $29.74 \mathrm{~m}^{2} \mathrm{~g}^{-1}$. The average particle size estimated from the specific surface area, assuming a spherical particle shape, was $9.34 \mathrm{~nm}$, which is in excellent agreement with that determined by XRD.

\section{$\mathrm{CV}$ and catalyst utilization}

Figure 1 shows a typical cyclic voltammogram obtained for the prepared electrode. As can be seen from this figure, two well-resolved $\mathrm{H}$-adsorption/desorption peaks are observed. One desorption peak is located at about $120 \mathrm{mV}$ and the other at about $250 \mathrm{mV}$. These two peaks are referred to be associated with the desorption of weakly and strongly adsorbed hydrogen atoms, respectively, in the literature [25].

The hydrogen adsorption/desorption Coulombic charge, $Q_{\mathrm{H}}$, was evaluated by integrating the charge transfer in the potential range between 50 and $400 \mathrm{mV}$ and subtracting the capacitive charge from the doublelayer charging $[20,26]$. As shown in Fig. $2, Q_{\mathrm{H}}$ determined at a scan rate of $25 \mathrm{mV} \mathrm{s}^{-1}$ corresponds linearly to the Pt-black loading of the electrode. Linear regression through the origin gave a slope of $0.06210 \pm 0.00032 \mathrm{mC} \mu^{-1}$ with a correlation coefficient of 0.9997 for the data in Fig. 2. For $100 \%$ catalyst utilization, the value of the slope should be identical

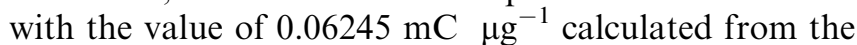
theoretical surface charge of $210 \mu \mathrm{C} \mathrm{cm}^{-2}$ for polycrystalline Pt surface [27] and the specific surface area of the Pt-black $\left(29.74 \mathrm{~m}^{2} \mathrm{~g}^{-1}\right)$. The agreement between these two values demonstrates that the utilization of the Pt-black catalyst is essentially $100 \%$.

In order to investigate the reproducibility of electrode preparation, $Q_{\mathrm{H}}$ measurements were performed for electrodes prepared independently with a Pt-black loading of $20 \mu \mathrm{g}$ (film thickness of $\sim 0.2 \mu \mathrm{m}$ ). The variation in $Q_{\mathrm{H}}$ has a standard deviation of $\pm 3.1 \%$ $(1.269 \pm 0.039 \mathrm{mC})$. This result indicates that the technique employed is sufficiently accurate for the evaluation of the electrochemical active surface area of an electrode.

It was found that as the Nafion film became thicker up to $8 \mu \mathrm{m}$, the same $Q_{\mathrm{H}}$ values (within the experimental errors) were obtained for electrodes with the same $\mathrm{Pt}$ loading $(20 \mu \mathrm{g})$ under the same scan rate $\left(25 \mathrm{mV} \mathrm{s} \mathrm{s}^{-1}\right)$. Although it is accepted that Nafion can block the electrochemical active sites for hydrogen adsorption/ desorption process, it seems also reasonable to assume
Fig. 1 Cyclic voltammogram of the Pt-black/Nafion electrode (Pt-black loading: $25 \mu \mathrm{g}$; Nafion film: $0.2 \mu \mathrm{m}$ ); scan rate $25 \mathrm{mV} \mathrm{s}{ }^{-1}$

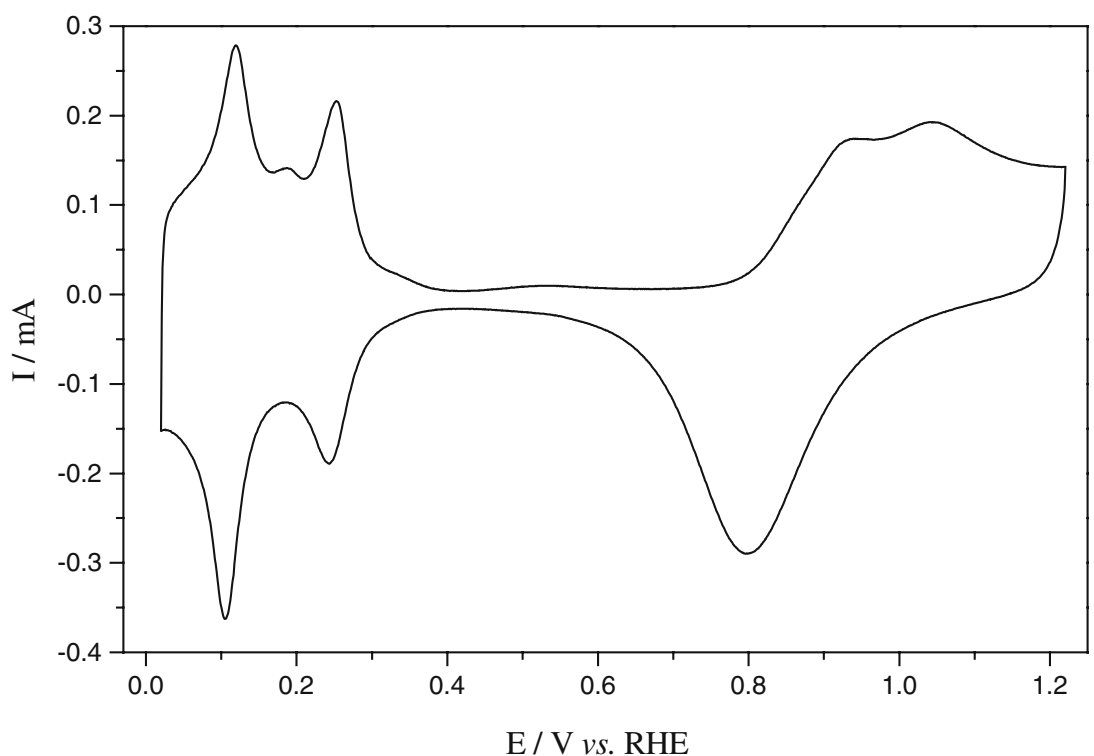


Fig. 2 The charge in the hydrogen adsorption/ desorption region versus Ptblack loading. Nafion film $\sim 0.2 \mu \mathrm{m}$; scan rate $25 \mathrm{mV} \mathrm{s}$ s. $^{-1}$

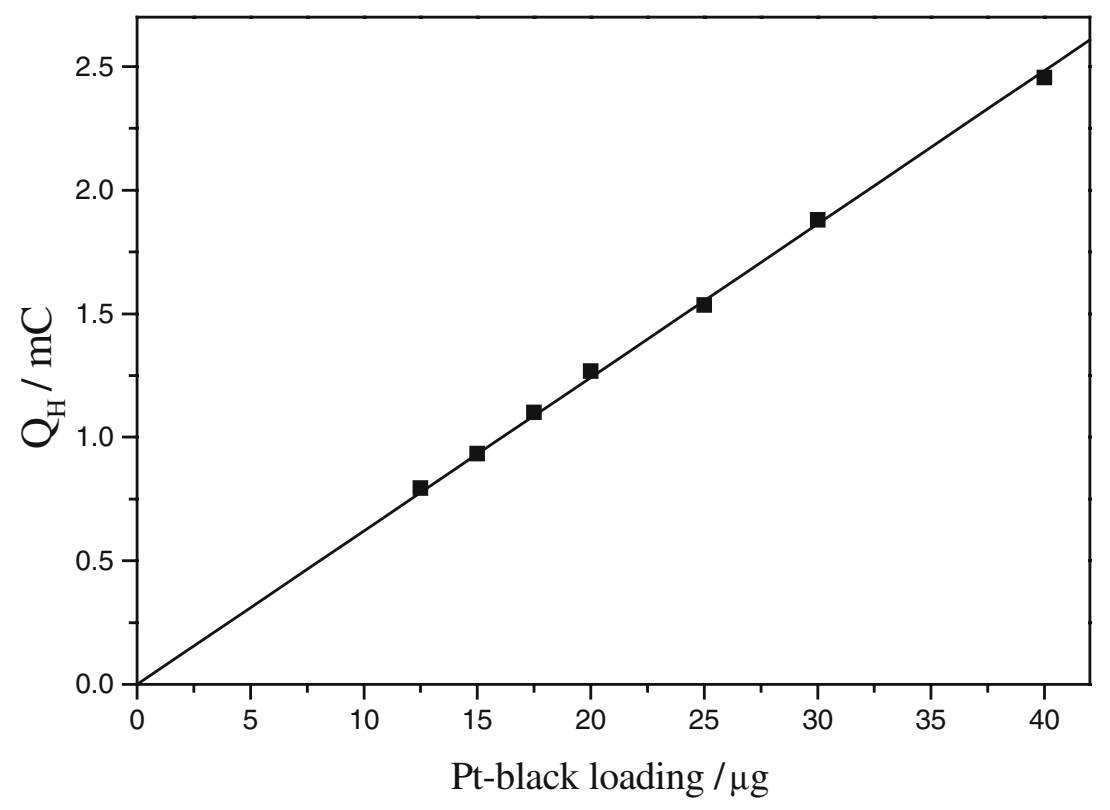

that only little penetration of the Nafion binder into the catalyst layer occurs, and the direct contact between the film and the catalyst layer is limited to the skin surface of the catalyst layer. Also, when the scan rate is sufficiently slow, the concentration of diffusing species would be homogeneous within the whole catalyst layer $[25,28]$; hence, the charges measured on the electrodes with the same Pt loading would be almost constant and independent of the Nafion film thickness. It was observed that when the scan rate was sufficiently high $(>50 \mathrm{mV}$ $\mathrm{s}^{-1}$ ), the catalyst utilization decreased with increasing scan rate.

\section{Hydrogen oxidation on RDE}

For a RDE without a Nafion film, the measured current density, $i_{\mathrm{m}}$, for the electrode reaction is given by

$\frac{1}{i_{\mathrm{m}}}=\frac{1}{i_{\mathrm{d}}}+\frac{1}{i_{\mathrm{k}}}$

where $i_{\mathrm{k}}$ represents the kinetic current density in the absence of mass transfer effect. The boundary-layer diffusion-limited current density, $i_{\mathrm{d}}$, can be expressed by the Levich equation [28]:

$i_{\mathrm{d}}=0.62 n F D^{2 / 3} v^{-1 / 6} C_{0} \omega^{1 / 2}=B C_{0} \omega^{1 / 2}$

where $n$ is the number of electrons involved in the electrode reaction, $F$ is the Faraday constant, $D$ is the reactant diffusivity in the electrolyte, $v$ is the electrolyte kinematic viscosity, $C_{0}$ is the reactant solubility in the electrolyte, and $\omega$ is the rotation rate in $\mathrm{rpm}$.

For a RDE with a Nafion film, besides the diffusion in the aqueous electrolyte, the diffusion in the Nafion film must be taken into account. The measured limiting current density, $i_{\mathrm{m}}$, for this case is given by $[13,20]$
$\frac{1}{i_{\mathrm{m}}}=\frac{1}{i_{\mathrm{d}}}+\frac{1}{i_{\mathrm{k}}}+\frac{1}{i_{\mathrm{f}}}=\frac{1}{B C_{0} \omega^{1 / 2}}+\frac{1}{i_{\mathrm{k}}}+\frac{1}{i_{\mathrm{f}}}$

where $i_{\mathrm{f}}$ represents the film-diffusion-limited current density controlled by reactant diffusion in the Nafion film. $i_{\mathrm{f}}$ is defined as

$i_{\mathrm{f}}=n F C_{\mathrm{f}} D_{\mathrm{f}} L^{-1}$

where $C_{\mathrm{f}}$ and $D_{\mathrm{f}}$ stand for the concentration and diffusion coefficient of the reactant in the film, respectively, and $L$ is the film thickness.

Equation 3 is a linear function of $\omega^{-1 / 2}$ with a slope equal to $1 / B C_{0}$ and an intercept, $Y_{0}$, corresponding to

$\frac{1}{Y_{0}}=\frac{1}{\frac{1}{i_{\mathrm{k}}}+\frac{1}{\left(n F C_{\mathrm{f}} D_{\mathrm{f}}\right) L^{-1}}}$

According to Eq. 5, 1/ $Y_{0}$ approaches to $i_{\mathrm{k}}$ when $L$ is sufficiently small or $L^{-1}$ is sufficiently large. Thus, the kinetic parameters of a reaction, $i_{\mathrm{k}}, B C_{0}$, and $C_{\mathrm{f}} D_{\mathrm{f}}$, can be estimated by analyzing the $i_{\mathrm{m}}$ data obtained at different rotation rates and film thicknesses using the above equations.

$\mathrm{H}_{2}$ oxidation experiments were conducted on the electrodes for which the Nafion film thickness ranged from 0.08 to $8 \mu \mathrm{m}$. The voltammograms for the electrodes (a Pt-black loading of $20 \mu \mathrm{g}$ ) with film thicknesses of 0.2 and $8 \mu \mathrm{m}$ are represented in Fig. 3a, b, respectively. The hysteresis loop of $\mathrm{H}_{2}$ oxidation currents between the anodic and cathodic scans was minute. For the reason of clarity, data for the cathodic scan, representing by a dashed line, are plotted only for the case of $400 \mathrm{rpm}$. One can see that the limiting current increases with increasing rotating rate and that the limiting current is smaller when the film is thicker at the same rotation rate.

Figure 4 shows a Koutecky-Levich plot [28] of the inverse of the limiting current density $\left(1 / i_{\mathrm{m}}\right)$ at $0.4 \mathrm{~V}$ vs. 
Fig. 3 Hydrodynamic voltammograms for $\mathrm{H}_{2}$ oxidation on the electrodes (Pt-black loading: $20 \mu \mathrm{g}$ ) with the film thicknesses of a $0.2 \mu \mathrm{m}$ and b $8 \mu \mathrm{m}$ in $\mathrm{H}_{2}$-saturated $0.5 \mathrm{M} \mathrm{H}_{2} \mathrm{SO}_{4}$ electrolyte; scan rate $5 \mathrm{mV} \mathrm{s}^{-1}$
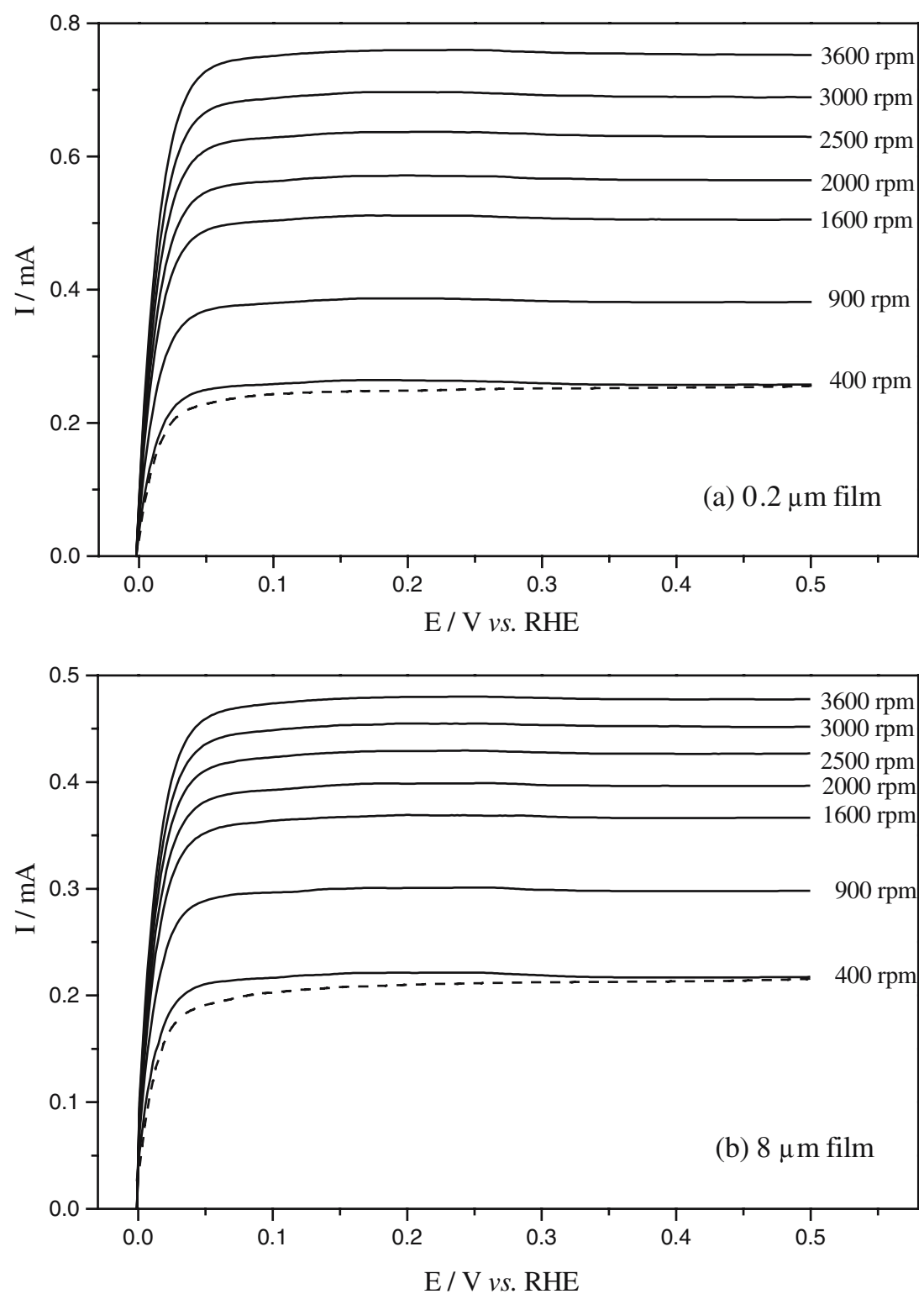

RHE vs. $\omega^{-1 / 2}$ for several film thicknesses. According to Eq. 3, a straight line should be obtained for each film thickness with a slope equal to $1 / B C_{0}$ and an intercept corresponding to $Y_{0}$. As demonstrated in the figure, the data agree very well with Eq. 3 and the slopes of the linear fitting lines are essentially equal. The average value of $B C_{0}$ determined, $6.62 \times 10^{-2} \mathrm{~mA} \mathrm{~cm} \mathrm{rpm}^{-1 /}$ ${ }^{2}( \pm 1.4 \%)$, is in excellent agreement with the theoretical value, $6.54 \times 10^{-2} \mathrm{~mA} \mathrm{~cm}^{-2} \mathrm{rpm}^{-1 / 2}$, reported by Gasteiger et al. [29].

Data of the inverse of $Y_{0}$ vs. $L^{-1}$ are plotted in Fig. 5. One can see that $1 / Y_{0}$ increases linearly in the $L^{-1}$ range from 0 to $0.6 \mu \mathrm{m}^{-1}$ and levels off after $5 \mu \mathrm{m}^{-1}$. Thus, $1 /$ $Y_{0}$ is equal to $i_{\mathrm{f}}$ when $L^{-1}$ is smaller than $0.6 \mu \mathrm{m}^{-1}$ (or $L \geq 1.7 \mu \mathrm{m})$ and equal to $i_{\mathrm{k}}$ when $L^{-1}$ is larger than $5 \mu \mathrm{m}^{-1}$ (or $L \leq 0.2 \mu \mathrm{m}$ ), according to Eq. 5. This result demonstrates that the electrocatalytic activity of the catalyst can be evaluated without the interference of the film diffusion for a film thickness smaller than $0.2 \mu \mathrm{m}$. The critical film thickness of $0.2 \mu \mathrm{m}$ is corresponding to a Pt-black loading of $20 \mu \mathrm{g}$; if the loading is lower, $i_{\mathrm{k}}$ would be smaller, and the critical thickness would be larger.

The average value of $i_{\mathrm{k}}$ evaluated from the data $\left(L^{-1} \geq 5 \mu \mathrm{m}^{-1}\right)$ in Fig. 5 was $88.6 \mathrm{~mA} \mathrm{~cm}^{-2}$, which is higher than the values $\left(40-60 \mathrm{~mA} \mathrm{~cm}^{-2}\right)$ obtained for smooth Pt RDEs [13, 22, 29]. In additional experiments, the $i_{\mathrm{k}}$ values obtained were in the range from 82.4 to $100 \mathrm{~mA} \mathrm{~cm}{ }^{-2}$. Thus, the average mass-specific current of the Pt-black was determined to be $0.91 \mathrm{~A} \mathrm{mg}^{-1}$ with $\pm 10 \%$ error.

From the nonlinear regression of the data points in Fig. 5 using Eq. 5, the value of $C_{\mathrm{f}} D_{\mathrm{f}}$ was determined to be $5.2 \times 10^{-5} \mathrm{mM} \mathrm{cm}^{2} \mathrm{~s}^{-1}$. Schmidt et al. [20] reported a $C_{\mathrm{f}} D_{\mathrm{f}}$ value of $7.8 \times 10^{-5} \mathrm{mM} \mathrm{cm}^{2} \mathrm{~s}^{-1}$ (their original value should be corrected by multiplying with 10 ) for a similar 
Fig. 4 Koutecky-Levich plots for $\mathrm{H}_{2}$ oxidation at $0.4 \mathrm{~V}$ vs. RHE on the electrodes (Pt-black loading: $20 \mu \mathrm{g}$ ) with several film thicknesses
Fig. 5 The inverse of Levich intercept as a function of the inverse of the Nafion film thickness
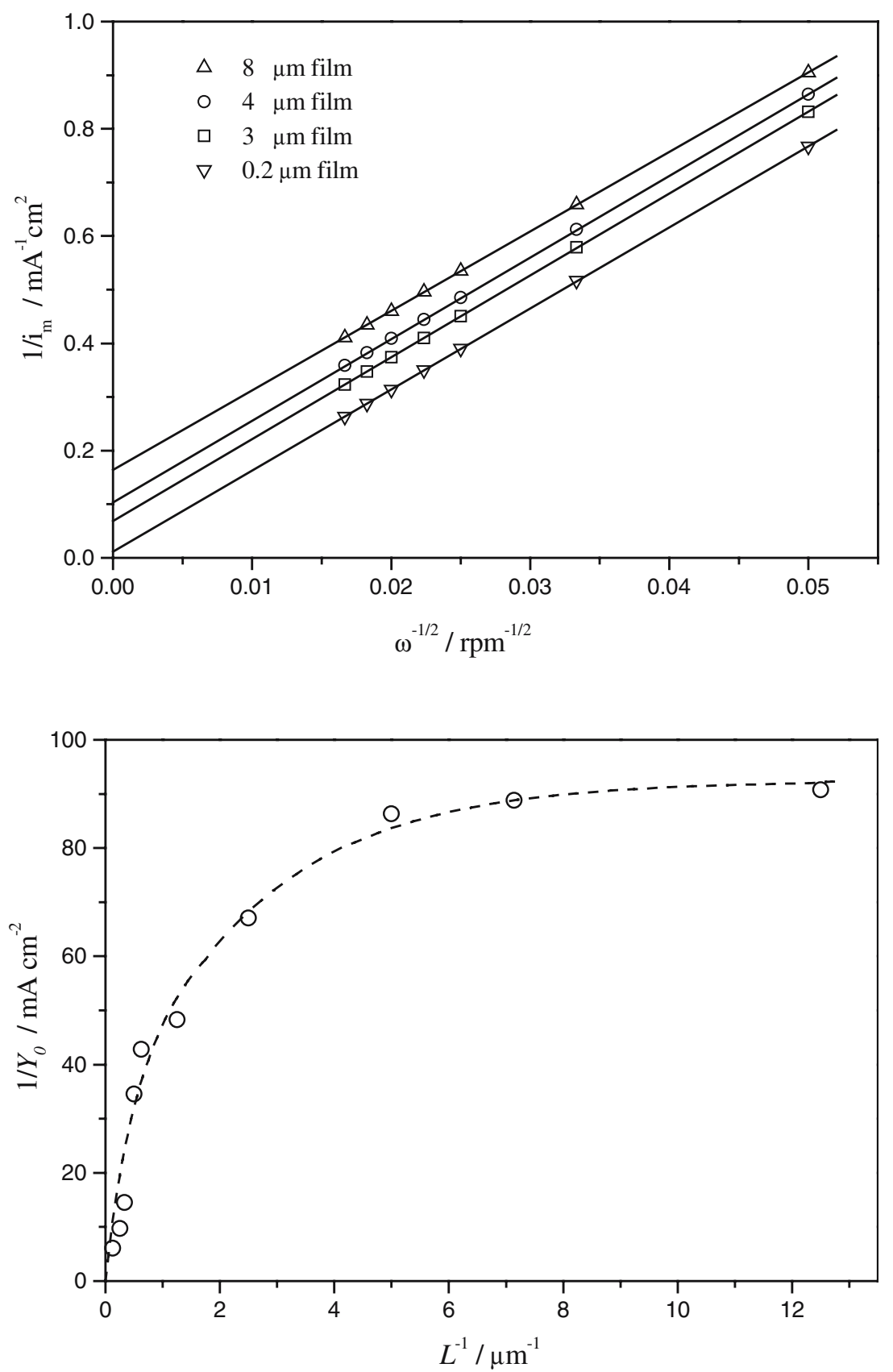

RDE configuration using a $20 \mathrm{wt} \% \mathrm{Pt} / \mathrm{C}$ catalyst. Comparing with those obtained in prior investigations $[13,14,30,31]$, however, our $C_{\mathrm{f}} D_{\mathrm{f}}$ value is higher. For instance, a $C_{\mathrm{f}} D_{\mathrm{f}}$ value of $4.7 \times 10^{-6} \mathrm{mM} \mathrm{cm}^{2} \mathrm{~s}^{-1}$ was reported by Watanabe et al. [13] using a Nafion coated smooth Pt electrode. This discrepancy probably can be explained by the difference in the structural properties of the Nafion film, such as the pore size and porosity, which are known to affect the diffusion of the reactant significantly.

It must be noted that the value of $i_{\mathrm{k}}$ estimated at a high overpotential is many-fold smaller than the true kinetic current density of $\mathrm{Pt}$ estimated at that overpotential, according to Schmidt and Gasteiger [22]. Hence, they attributed their $i_{\mathrm{k}}$ values determined at $0.2 \mathrm{~V}$ vs. RHE to the error in $Y_{0}$ and the residual resistance due to the thin Nafion film. However, Watanabe et al. [13] attributed the low values of $i_{\mathrm{k}}$ determined at $0.4 \mathrm{~V}$ vs. RHE to representing some rate-limiting chemical processes preceding or following the electron transfer process in $\mathrm{H}_{2}$ oxidation reaction. Our results, showing $\pm 10 \%$ error in $Y_{0}$, seem to agree with the latter explanation.

Because the value of $i_{\mathrm{k}}$ is much larger than that of $i_{\mathrm{m}}$, the value of $i_{\mathrm{k}}$ determined from the data of $i_{\mathrm{m}}$ is inherently subjected to a large uncertainty. The uncertainty can be reduced by reducing the $i_{\mathrm{k}} / i_{\mathrm{m}}$ ratio, by means of using lower catalyst loading, higher rotation rate, and thinner polymer film. 
The geometric structure of the Pt-black/Nafion deposit on the disk is also an important factor affecting the uncertainty of the $i_{\mathrm{k}}$ value. In deducing the value of $i_{\mathrm{k}}$ by means of Eqs. 3, 4, 5, the mass-transport equations representing $i_{\mathrm{d}}$ (Eq. 2) and $i_{\mathrm{f}}$ (Eq. 4) are valid only for uniform layer thickness and flat surface. But, the deviation from the idea case is unavoidable in practice and different extent of deviation may result, depending on the operation of the deposition process. Thus, the carefulness in the deposition process will reduce the uncertainty and improve the reproducibility of the $i_{\mathrm{k}}$ value determined.

\section{Conclusions}

We have investigated the electrochemical behavior of Ptblack (specific surface area $=29.74 \mathrm{~m}^{2} \mathrm{~g}^{-1}$ ) and its electrocatalytic activity towards $\mathrm{H}_{2}$ oxidation when it is covered by Nafion, using a RDE and CV technique. This method has been demonstrated to be efficient and accurate for characterizing the electrochemical surface area of the catalyst and evaluating its intrinsic activity under fuel cell relevant conditions.

The voltammetric results showed that Pt-black without direct contact with Nafion is still electrochemically active in taking part in the $\mathrm{H}$-adsorption/desorption process. For $\mathrm{H}_{2}$ oxidation, the limiting current density was reduced by the presence of Nafion coating. The effect of $\mathrm{H}_{2}$ diffusion resistance in the Nafion film became negligible when the film thickness was smaller than $0.2 \mu \mathrm{m}$ for a Pt-black loading of $20 \mu \mathrm{g}$.

This study provides the basic data for designing an electrode for PEMFCs using Pt-black catalyst.

Acknowledgements The authors would like to express sincere appreciation to the National Science Council of Republic of China (Taiwan) for the financial support. We also thank Mr. Ying-Chan Hsu and Ricon Yen for the technical support.

\section{References}

1. Ralph TR (1997) Platinum Metals Rev 41:102

2. Kordesch K, Simader G (1996) Fuel cells and their application. $\mathrm{VCH}$, New York

3. Mehta V, Cooper JS (2003) J Power Source 114:32
4. Ticianelli EA, Derouin CR, Redondo A, Srinivasan S (1988) J Electrochem Soc 135:2209

5. Wilson MS, Gottesfeld S (1992) J Electrochem Soc 139:L28

6. Wilson MS, Gottesfeld S (1992) J Appl Electrochem 22:1

7. Uchida M, Aoyama Y, Eda N, Ohta A (1995) J Electrochem Soc 142:463

8. Wilson MS, Valerio JA, Gottesfeld S (1995) Electrochim Acta 40:355

9. Uchida M, Aoyama Y, Eda N, Ohta A (1995) J Electrochem Soc 142:4143

10. Thomas SC, Ren X, Gottesfeld S (1999) J Electrochem Soc $146: 4354$

11. Passalacqua E, Lufrano F, Squadrito G, Patti A, Giorgi L (2001) Electrochim Acta 46:799

12. Sasikumar G, Ihm JW, Ryu H (2004) J Power Source 132:11

13. Watanabe M, Igarashi H, Yosioka K (1995) Electrochim Acta 40:329

14. Maruyama J, Inaba M, Katakura K, Ogumi Z, Takehara Z (1998) J Electroanal Chem 447:201

15. Gottesfeld S, Raistrick ID, Srinivasan S (1987) J Electrochem Soc 134:1455

16. Lawson DR, Whiteley LD, Martin CR (1988) J Electrochem Soc $135: 2247$

17. Zecevic SK, Wainright JS, Litt MH, Gojkovic SLj, Savinell RF (1997) J Electrochem Soc 144:2973

18. Gloaguen F, Andolfatto R, Durano PO (1994) J Appl Electrochem 24:863

19. Gojkovic SLj, Zecevic SK, Savinell RF (1998) J Electrochem Soc $145: 3713$

20. Schmidt TJ, Gasteiger HA, Stab GD, Urban PM, Kolb DM, Behm RJ (1998) J Electrochem Soc 145:2354

21. Schmidt TJ, Gasteiger HA, Behm RJ (1999) J Electrochem Soc 146:1296

22. Schmidt TJ, Gasteiger HA (2003) Rotating thin-film method for supported catalysts. In: Vielstich W, Gasteiger HA, Lamm A (ed) Handbook of fuel cells-fundamentals, technology and applications, vol 2. Wiley, New York, pp 316-333

23. Zook LA, Leddy J (1996) Anal Chem 68:3793

24. Cullity BD (1978) Elements of X-ray diffraction. Addison Wesley, New York

25. Tu WY, Liu WJ, Cha CS, Wu BL (1998) Electrochim Acta 43:3731

26. Nart FC, Vielstich W (2003) Normalization of porous active surfaces. In: Vielstich W, Gasteiger HA, Lamm A (ed) Handbook of fuel cells- fundamentals, technology and applications, vol 2. Wiley, New York, pp 302-315

27. Bagotsky VS, Vassilyev YB (1967) Electrochim Acta 12:1323

28. Bard AJ, Faulkner LR (2001) Electrochemical methods-fundamentals and applications. Wiley, New York

29. Gasteiger HA, Markovic NM, Ross PN (1995) J Phys Chem 99:8290

30. Ogumi Z, Kuroe T, Takehara Z (1985) J Electrochem Soc 132:2601

31. Fritts SD, Gervasio D, Zeller RZ, Savinell RF (1991) J Electrochem Soc 138:3345 